\title{
Immunochemical detection of the crustacean cardioactive peptide in the cephalic ganglia of cockroaches (Blattodea: Blattidae)
}

\author{
MARcin GLADYSZ ${ }^{1}$, JoANnA GUZIK ${ }^{1}$, HANA SEHADOVÁ ${ }^{2}$, BARTOSZ BARAN ${ }^{1}$, JADWIGA BEMBENEK $^{1}$ \\ and BogDAN DOLEZYCH ${ }^{1}$
}

\begin{abstract}
${ }^{1}$ Department of Animal Physiology and Ecotoxicology, Faculty of Biology and Environmental Protection, University of Silesia, Bankowa 9, 40-007 Katowice, Poland; e-mails: marcin.gladyszz@gmail.com, joannaguzik6@wp.pl, bartosz.m.baran@gmail.com; jadwigabembenek@hotmail.com; bogdan.dolezych@us.edu.pl

${ }^{2}$ Department of Molecular Biology and Genetics, Institute of Entomology, Biology Centre CAS, 37005 Ceske Budejovice, Czech Republic; e-mail: sehadova@yahoo.com
\end{abstract}

Key words. Blattodea, Periplaneta americana, Gromphadorhina portentosa, cockroach, CCAP, neuropeptides

\begin{abstract}
In insects, the crustacean cardioactive peptide (CCAP) is involved mainly in the regulation of ecdysis and is both a hormone secreted into the haemolymph and a neuromodulator or neurotransmitter in the nervous system. However, this peptide has only been recorded in the brains of a few species of insects. The present study examined the distribution of CCAP in the cephalic ganglia of the cockroach, Periplaneta americana, using two kinds of specific antibodies. The antibody directed against synthetic CCAP detected a large number of CCAP-immunoreactive neurons in the protocerebrum, deutocerebrum, tritocerebrum, suboesophageal ganglion, optic lobes, frontal ganglion and neurohemal organs, while the antibody directed against CCAP precursor (pre-propeptide) stained only a few neurons within the central brain and frontal ganglion. The latter antibody also revealed similar sets of neurons in another species of cockroach, Gromphadorhina portentosa, and identified the CCAP precursor of approximately $15 \mathrm{kDa}$ in size in Western blot analyses.
\end{abstract}

\section{INTRODUCTION}

CCAP (crustacean cardioactive peptide) is a neuropeptide occurring in arthropods and molluscs. It is characterized by a wide range of functions and affects many physiological processes. CCAP was first described by Stangier et al. (1987), as a hormonal substance that stimulates the heart action of the crab, Carcinus maenas. Following findings indicate that CCAP is a molecule with neurotransmitter or neuromodulator properties. CCAP occurs in neurons in the central nervous system of insects (Stangier et al., 1989) and in interneurons in the central nervous system of crustaceans (Stangier et al., 1988) and insects (Breidbach \& Dircksen, 1991). CCAP was found in nerves innervating the gut of the locust Locusta migratoria (Donini et al., 2002) and in the midgut endocrine cells of the cockroach Periplaneta americana (Sakai et al., 2004). Veelaert et al. (1997) demonstrate that in the locust CCAP induces the corpora cardiaca to release AKH. This neuropeptide also influences oviduct contractions in L. migratoria (Donini et al., 2001).

Although CCAP is a potent cardioaccelerator in crustaceans, its effect on the heart of insects is not so clear (Dulcis et al., 2005; Sláma \& Rosiński, 2005; Da Silva et al., 2011). However in some insects, CCAP has a cardioacceleratory effect (Furuya et al., 1993; Lehman et al., 1993; Estévez-Lao et al., 2013), whereas in the cockroach P. americana, it does not appear to affect the circulatory system (Sláma et al., 2006).

There are many studies on the participation of CCAP in ecdysis. Moulting is regulated by steroid hormones, but the initiation and rhythmicity of this process is controlled by neuropeptides. CCAP participation in this process was first shown in insects: the tobacco hawkmoth Manduca sexta (Gammie \& Truman, 1997) and two crustaceans: the crab C. maenas and crayfish Orconectes limosus (Phlippen et al., 2000). Subsequent studies confirmed the important role of CCAP and other peptides in this process (Arakane et al., 2008).

CCAP is a cyclic amidated nonapeptide. The cyclic shape of this peptide is due to disulfide bridges connecting the ends of the peptide (Jackson et al., 2009). Slightly longer forms, M-CCAP1 and M-CCAP2, occur in molluscs, but their structure is similar to arthropod CCAP (Vehovszky et al., 2005). Bioactive peptides are generated via enzymatic cleavage and modification pathways from inactive peptide precursors (propeptides). CCAP propetides are synthesized with an N-terminal signal peptide that targets them for secretion and thus their name is prefixed by pre (prepropeptides). Although the amino acid sequence of CCAP is identical in different species the structure of the CCAP pre-propeptide is not as conservative. The gene encoding CCAP was first identified in M. sexta (Loi et al., 2001) and two years later the CCAP receptor was described in Drosophila (Cazzamali et al., 2003), but its similarity with the vasopressin receptor had been previously proposed based on bioinformatics (Park et al., 2002). There are two functionally different CCAP receptors in the flour beetle (Tribolium castaneum) (Lee et al., 2011).

The role of CCAP has been studied from different aspects in cockroaches, which are suitable models for physi- 
ological studies. These studies revealed that CCAP is not a potent cardioacceleratory factor but participates in the regulation of the activity of digestive enzymes (Sakai et al., 2004, 2006; Sláma et al., 2006; Matsui et al., 2013). Its role in digestion, is supported by the presence of CCAP in endocrine cells in the midgut, but there is no information on the distribution and function of CCAP in the central nervous system of cockroaches. This study describes the immunohistochemical detection of both the CCAP prepropeptide and active CCAP in the cephalic ganglia of the cockroaches $P$. americana, Gromphadorhina portentosa and $P$. americana respectively.

\section{MATERIAL AND METHODS}

\section{Insects}

The cockroaches Periplaneta americana and Gromphadorhina portentosa were reared in a controlled environment $\left(30^{\circ} \mathrm{C}\right.$ and $60 \%$ relative humidity) under a $12 \mathrm{~L}: 12 \mathrm{D}$ cycle. Insects were fed ad libitum with food for laboratory animals (Agropol, Poland). Only adult insects were used in the experiments. Samples were collected in the middle of the light phase of the light : dark cycle and for the immunohistochemical detection of active CCAP also in the middle of the dark phase.

\section{Antibodies}

The rabbit polyclonal IgG antibody directed against the CCAP pre-propeptide was purchased from Abcam, Cambridge, UK. According to the manufacturer this antibody was developed against synthetic immunogen with the peptide sequence: IMSQAKIFEAIKEASKEIF, which corresponds to the conserved region of D. melanogaster CCAP pre-propeptide (Fig. 3). Immunohistochemical specificity of this antibody to endogenous antigen was tested by the manufacturer using third instar larvae of Drosophila. For detecting active CCAP the rabbit polyclonal IgG antibody directed against CCAP (Genemed Synthesis, San Francisco, CA) was used. The specificity of this antibody is confirmed by several studies (Sakai et al., 2004; Sehadova et al., 2007; Matsui et al., 2013).

\section{Immunohistochemistry}

Insects were immobilized on ice and decapitated. The brains with the suboesophageal ganglion, frontal ganglion and neurohemal organs attached were dissected in physiological saline solution $(0.15 \mathrm{M} \mathrm{NaCl})$ and fixed immediately in Bouin solution (BS, for pre-propeptide detection) or in a modified Bouin-Hollande solution (BHS) without acetic acid, but supplemented with $0.7 \%$ mercuric chloride (for detection of final peptide), overnight at $4^{\circ} \mathrm{C}$. Standard histochemical techniques were used for tissue dehydration, embedding in paraplast, sectioning ( 7 to $12 \mu \mathrm{m}$ ), deparaffinization and rehydration. The sections of tissues fixed in BHS were then treated with Lugol's iodine followed by a $7.5 \%$ solution of sodium thiosulphate to remove residual heavy metal ions from the fixed tissue and then washed in distilled water and tris-buffered saline (TBS). The rehydrated sections of samples fixed in BS were directly equilibrated in TBS. Immunocytochemistery was done using a Rabbit IgG-Vectastain Elite ABC kit (Vector Laboratories, Burlingame, CA). The sections were blocked with $1.5 \%$ normal goat serum diluted in TBS for $30 \mathrm{~min}$ at room temperature (rT) and incubated with primary antibody (diluted 1:500 anti-CCAP pre-propeptide or 1:1000 anti-CCAP in blocking serum) in a humidified chamber overnight at $4^{\circ} \mathrm{C}$. In control experiments, the primary antibody was replaced with normal serum. After thorough rinsing with TBS (three times each for $10 \mathrm{~min}$ at $\mathrm{rT}$ ), the sections were first incubated with a bioti- nylated secondary antibody diluted $1: 200$ in blocking serum for $1 \mathrm{~h}$ at rT, washed in TBS (three times each for $10 \mathrm{~min}$ at $\mathrm{rT}$ ) and then treated with horseradish peroxidase (HRP)-labelled avidinbiotin complex (diluted in TBS supplemented with $0.1 \%$ Tween 20) for $40 \mathrm{~min}$ at $\mathrm{rT}$. Following rinsing with TBS (three times each for $10 \mathrm{~min}$ at $\mathrm{rT}$ ) and with $0.1 \mathrm{M}$ Tris- $\mathrm{HCl}, \mathrm{pH} 7.5$ (10 min at $\mathrm{rT}$ ), the HRP enzymatic activity was visualized using hydrogen peroxide $(0.01 \%)$ and 3,3 '-diaminobenzidine tetrahydrochloride (DAB, $0.25 \mathrm{mM}$ in $0.1 \mathrm{M}$ Tris-HCl, $\mathrm{pH} 7.5$ ) as a chromogen. Stained sections were dehydrated and mounted in Canada balsam (Carl Roth, Karlsruhe, Germany) or Bioleit mounting medium (Kouken, Osaka, Japan).

\section{Western blot analysis}

Brains of twenty cockroaches were dissected in $0.15 \mathrm{M} \mathrm{NaCl}$ and homogenized. The concentration of extracted proteins was determined according to Bradford (1976) using bovine serum albumin (BSA) as the protein standard. The protein extract containing $30 \mu \mathrm{g}$ of protein was separated using SDS-PAGE for $45 \mathrm{~min}$ at $30 \mathrm{~V}, 70 \mathrm{~min}$ at $50 \mathrm{~V}$ and $4 \mathrm{~h}$ at $80 \mathrm{~V}$, respectively (MiniProtean II, BioRad). Proteins were then transferred onto a PVDF membrane (Hybond ${ }^{\mathrm{TM}}$-LFP, GE Healthcare) at $300 \mathrm{~mA}$ for $2 \mathrm{~h}$ with a wet transfer system (Mini Transfer-Blot, BIO-RAD, CA). Membrane was blocked for $1 \mathrm{~h}$ at $\mathrm{rT}$ with $1 \%$ BSA in TBS and incubated with the anti-CCAP pre-propetide antibody at a dilution of $1: 10000$, in $1 \% \mathrm{BSA}$ in TBS, overnight at $4^{\circ} \mathrm{C}$ with continuous shaking. After rinsing in TBS supplemented with $0.1 \%$ Tween 20 (TBS-T, $4 \times 10 \mathrm{~min}$ at $\mathrm{rT}$ ), the membrane was incubated for $1 \mathrm{~h}$ at $\mathrm{rT}$ with alkaline phosphatase conjugated goat anti-rabbit IgG $\left(\right.$ Novagen $^{\circledR}$, San Diego, CA) at a dilution of $1: 20000$ in TBS. Following rinsing in TBS-T $(4 \times 10 \mathrm{~min}$ at $\mathrm{rT})$, protein bands were visualized using colorimetric substrate solutions of nitro-blue tetrazolium and 5-bromo-4-chloro-3'-indolyphosphate (NBT/BCIP; Thermo Fisher Scientific Inc., Rockford, IL).

\section{Bioinformatics}

The amino acid sequences (conceptual translations) of CCAP precursors of selected insect species (Diptera: Drosophila melanogaster, Anopheles gambiae; Lepidoptera: Galleria mellonella, Bombyx mori, Manduca sexta; Coleoptera: Tribolium castaneum; Hemiptera: Rhodnius prolixus; Blattodea: Periplaneta americana) were obtained from GenBank database (NCBI, National Center for Biotechnology Information, http://www.ncbi.nlm. nih.gov/, collected 22.06.2014). Calculations of the molecular weight, $\mathrm{pI}$ and sequence length were performed using the bioinformatics tools available on website Protein Calculator - The Scripps Research Institute (http://www.scripps.edu/ cdputnam/ protcalc.html, collected 22.06.2014). A multiple amino acid sequence alignment of CCAP precursors was constructed using the ClustalW algorithm (http://clustalw.ddbj.nig.ac.jp/) and BioEdit software.

\section{RESULTS}

\section{CCAP pre-propeptide in the brain of $P$. americana and G. portentosa}

An immunohistochemical investigation of $P$. america$n a$ and $G$. portentosa, using an antibody directed against CCAP pre-propeptide, revealed the occurrence of the antigen in identically located neurons within the protocerebrum and deutocerebrum. A pair of bilaterally located intensely stained neurons was detected in the ventrolateral protocerebrum in the vicinity of the optic lobe (Figs 1A, C, 2D) and a bilateral cluster of about 10 cells in the dorsal median deutocerebrum close to the antennal lobe (Figs 1F, 

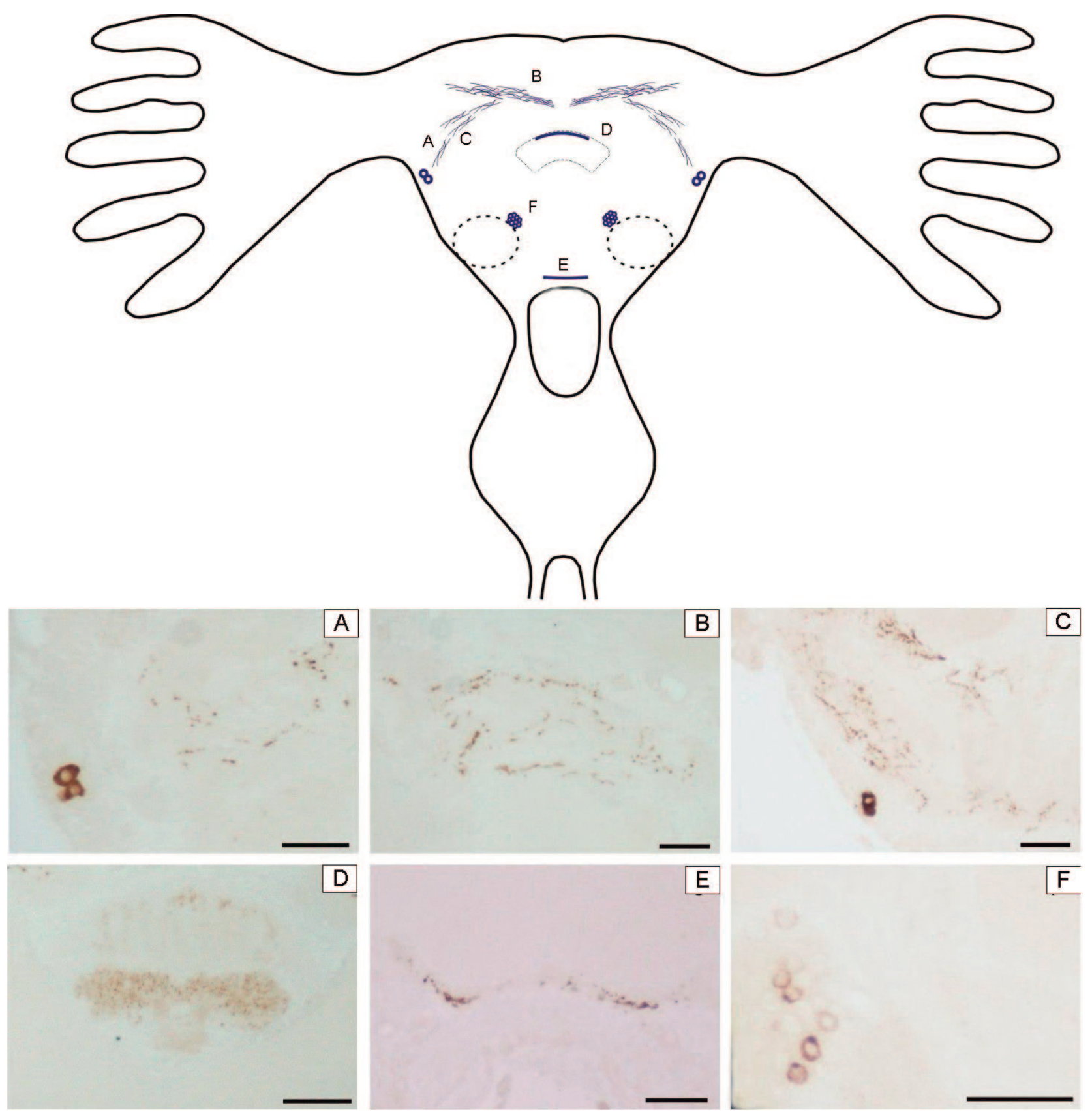

Fig. 1. Immunodetection of the CCAP pre-propeptide in the brain of $P$. americana. A schematic diagram illustrating the topography of immunolabelled cells in the adult brain (A-F positions of the respective micrographs in this figure). A - strongly stained CCAPpositive cells in the ventrolateral part of the protocerebrum; B, C - extensive arborization in the protocerebrum; D - ramification of fibres within the central body; E - axonal bundles leading to the corpora cardiaca in the posterioventral brain area; F - a cluster of CCAP-positive cells in the vicinity of the antennal lobe. Scale bar $100 \mu \mathrm{m}$.

2B). The protocerebrum contains an extensive network of fibres (Figs 1A, B, C, 2E). This mesh of fibres embraces mushroom bodies and in the median protocerebrum condenses into a nerve bundle that passes through the pars intercerebralis into the contralateral hemisphere (Figs 1B, 2E). The arborisation was recorded in the lower (intense in $P$. americana) and upper divisions of the central body (intense in $G$. portentosa). In $G$. portentosa one bilateral neuron was situated in the median protocerebrum close to the calyx of the mushroom body (Fig. 2C) and in the lateral ventral tritocerebrum (Fig. 2F).
The specificity of the antibody was verified using Western blot analysis of proteins extracted from the head of $G$. portentosa. Immunoblotting on a PVDF membrane revealed a band with an approximate size of $15 \mathrm{kDa}$ (Fig. 4), which is close to the size of CCAP precursors identified by in silico analysis in other species of insect. The size of the CCAP precursor ranges from $14.2 \mathrm{kDa}$ in the greater wax moth Galleria mellonella to $19.5 \mathrm{kDa}$ in P. americana and the length of the amino acid sequence of the CCAP precursor varies from 126 amino acids in the silkworm Bombyx mori to 171 amino acids in $P$. americana (Table 1). Amino 



Fig. 2. Immunodetection of CCAP pre-propeptide in the brain of G. portentosa. A schematic diagram illustrating the topography of immunolabelled cells in the adult brain (A-F positions of the respective micrographs in this figure). A-ramification of fibres within the central body; $\mathrm{B}$ - a cluster of CCAP-positive cells in vicinity to the antennal lobe; $\mathrm{C}$ - a single CCAP-positive cell in the central brain under the calyx of the mushroom body; D - CCAP-positive cells in ventrolateral part of the protocerebrum; E - extensive arborization passing through the pars intercerebralis; F - tritocerebrum with a single CCAP-positive cell. Scale bar $100 \mu \mathrm{m}$.

acid sequence alignment revealed that in P. americana, the C-terminus of the pre-propeptide contains amino acids that are absent in other species of insects (Fig. 3).

\section{CCAP peptide in the cephalic ganglion of $P$. americana}

The antibody directed against synthetic CCAP detected a widespread distribution of CCAP-immunoreactive neurons in the whole cephalic ganglion. Each optic lobe was weakly CCAP-positively stained in a cluster of about 5 large and 5 small neurons in the proximal frontal ventral part, next to the accessory medulla and in one small cell in proximal frontal dorsal region (Fig. 5B, C, D). These neurons may be connected to the extensive arborization that embraces a small area on the lateral edge of the lobula and/or with the fine varicosities in the distal layers of the lobula division (Fig. 5B, D). From the lobula, the fine immunoreactive fibres run through the medulla into the lamina and form fine varicosities within the medial part of the medulla and over the inner lamina surface (Fig. 5D). Other fibres pass through the optic tract to the central brain. Three groups of up to 10 neurons were detected in the posterior lateral protocerebrum, two of which are located lateral to the calyx in the mushroom body. The first cluster is slightly lateral to the second and both are weakly to moderately stained 
TABLE 1. Properties of CCAP pre-propeptide of selected insect species. The amino acid sequences of CCAP precursors were obtained from GenBank database (http://www.ncbi.nlm.nih.gov). Calculations of molecular weight, pI and sequence length (AA) were performed by using bioinformatics tools available on a website The Scripps Research Institute (http://www.scripps.edu/ ${ }^{\sim} \mathrm{cdputnam} /$ protcalc.html).

\begin{tabular}{lcccc}
\hline Taxon & Accession number & MW (kDa) & Estimated pI & Sequence length (aminoacids) \\
\hline Galleria mellonella & AEZ02304.1 & 14.248 & 8.08 & 127 \\
Bombyx mori & NP_001124369.1 & 14.305 & 6.62 & 126 \\
Tribolium castaneum & ADM26614.1 & 16.105 & 5.97 & 146 \\
Rhodnius prolixus & ADK73625.1 & 14.813 & 7.84 & 129 \\
Periplaneta americana & BAD18887.1 & 19.466 & 7.80 & 171 \\
Anopheles gambiae & AGG10332.1 & 17.854 & 7.80 & 160 \\
Manduca sexta & AAL39064.1 & 14.022 & 6.62 & 125 \\
Drosophila melanogaster & NP 651083.2 & 18.043 & 8.64 & 155 \\
\hline
\end{tabular}

(Fig. 5D, E). The third cluster is in the ventral lateral protocerebral cortex in close vicinity of the ventral part of the optic tract and contains cells that are among the most intensely stained CCAP-positive neurons. The neuronal projections from these cells form a strong nerve bundle that runs into the lateral region of the brain (Fig. 5F). Another 4-5 neurons are slightly ventrally positioned in the base of the optic tract (Fig. 5D). Weak immunoreactivity was recorded in the anterior dorsal lateral protocerebrum in up to 25 neurons of various sizes (Fig. 5G). Most prominent immunostaining was recorded in 5 bilaterally symmetrical neurons within the somata in the posterior pars intercerebralis. Three of them are large and are neighbouring cells (Fig. 5H). Surrounding them are 40-50 cells of similar size the staining of which varied from weak to strong (Fig. 5I). Around 3 large and up to 10 small CCAP-positive cells occurred in the anterior cortex of the midbrain (Fig. 5J). A group of about 70 large and small immunoreactive neurons that are moderately stained occur in the anterior pars intercerebralis (Fig. 5K). Two large and two small CCAP-positive perikarya were found in the border area of the proto- and deutocerebrum dorsal lateral to the antennal lobe (Figs $5 \mathrm{~L}, \mathrm{M}$ ). Another approximately 5 small cells occur in the median deutocerebrum (Fig. $5 \mathrm{~N}$ ). There are up to 15 small neurons in the lateral tritocerebrum (Fig. 6A). Their axons give rise to a wide arborization in the ventral area of the tritocerebrum and pass contralaterally through the frontal connective into the frontal ganglion, where they extensively ramify and give rise to fibres in the recurrent nerve (Fig. 6B). Almost all the cells in the frontal ganglion contain CCAP-positive material but only 4-5 neurons stained intensively (Fig. 6C). Their axons end in an arborization within the frontal ganglion, therefore it is possible they pass into the recurrent nerve or tritocerebrum. Outside the central brain CCAP-positive staining was detected in a large number of neurons mainly in the peripheral region of the suboesophageal ganglion (SOG). There are two large CCAP-positive perikarya in the anterior part of the SOG (Fig. 6D). The posterior part contains about 8 large and up to 20 small immunoreactive neurons that are differently stained. The large neurons usually show a stronger immunoreactivity than the small neurons (Fig. 6E). Two strongly stained cells and up to 20 moderately stained cells of various sizes occur on the ventral posterior surface of the SOG

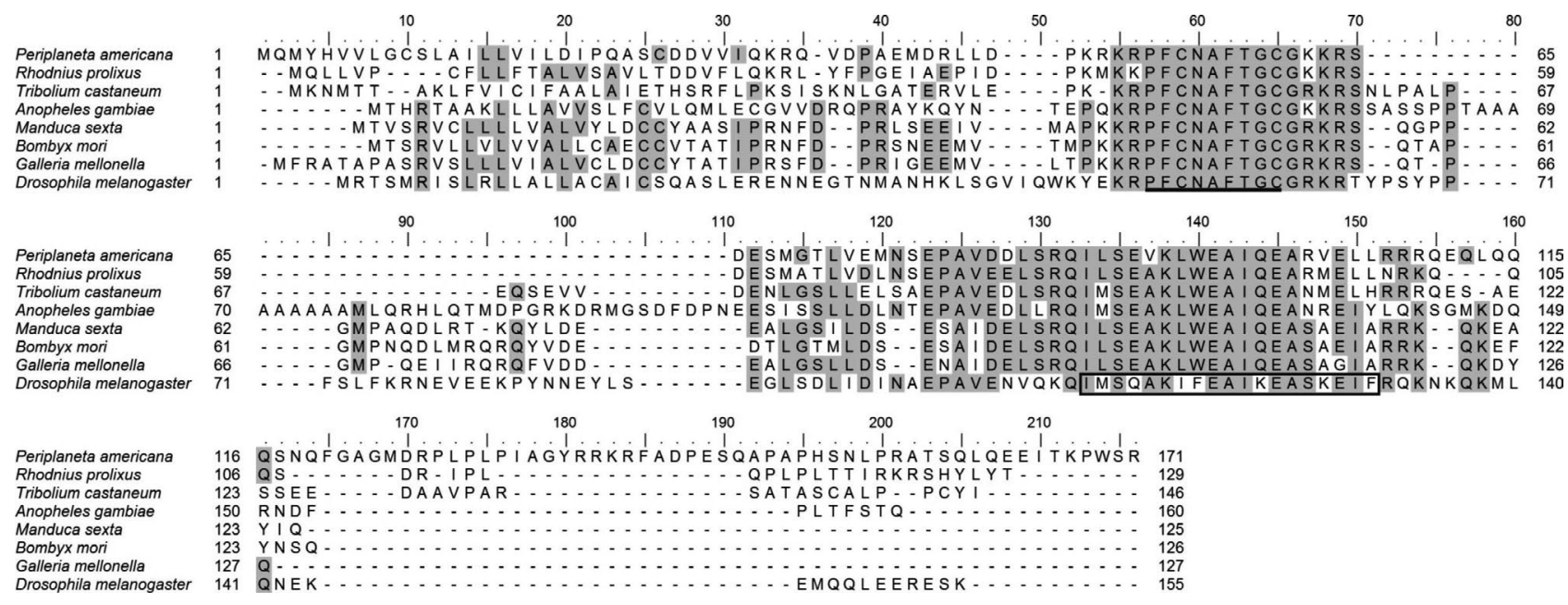

Fig. 3. The amino acid sequence alignment of CCAP pre-propeptide of selected insect species. The sequences were obtained from the GenBank database. A multiple amino acid sequence alignment of CCAP precursors was constructed using the ClustalW algorithm (http://clustalw.ddbj.nig.ac.jp/) and BioEdit software. Two conserved regions occur in the amino acid sequence of CCAP pre-propeptides: Firstly, the amino acid sequence of the active peptide, is located in the central region of the protein. Secondly, the sequence that probably plays a regulatory role in the processing of pre-propeptides, is located close to the C-terminus of the protein. Identical amino acid residues are highlighted in grey. Sequence of the active peptide is underlined and the antigen recognized by the antibody directed against CCAP pre-propeptide is boxed. 


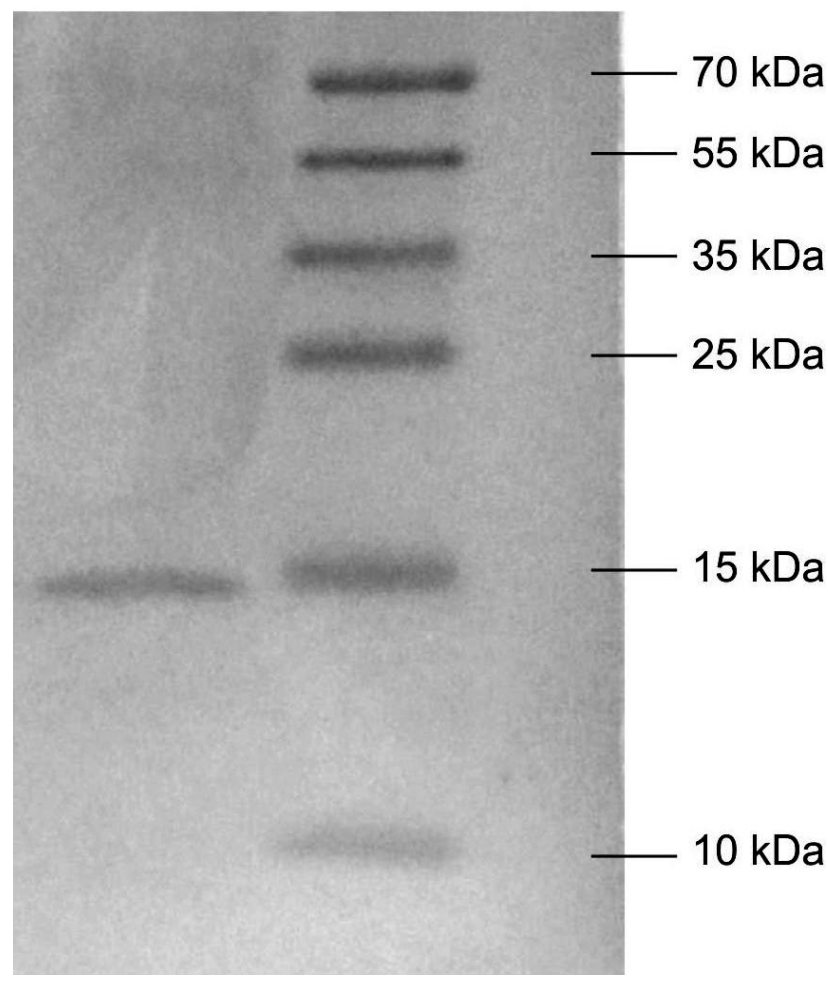

Fig. 4. CCAP pre-propeptide immunodetection using Western blot of proteins extracted from the heads of G. portentosa. The antibody directed against CCAP pre-propeptide revealed a highly visible band of about $15 \mathrm{kDa}$ (line 1). The position of molecular weight markers are shown in line $\mathrm{M}$.

(Fig. 6F, G). On each dorsal lateral part of the SOG there are 2 large and about 4 small strongly stained neurons (Fig. $6 \mathrm{H}, \mathrm{I}, \mathrm{J})$. The axonal projections of the small cells extend to the median part of the SOG (Fig. 6I) and two of these cells are situated close to the large neurons that occur in the region of the maxillary and labial neuromere. The whole of the SOG and all of the main parts of the central brain are innervated by a network of CCAP-immunoreactive neuronal processes and fibres (Fig. 6K, L, H). CCAP immunoreactivity was recorded in the wide arborization in the corpora cardiaca and corpora allata (Fig. 6K, L) and the varicose fibres in the nervi corporis cardiaci and nervi corporis allati (Fig. 6M).

A detailed immunocytochemical examination of the CCAP immunoreactivity during a light-dark cycle did not reveal a daily oscillation in the abundance of cytoplasmic CCAP-like antigen. The distribution and number of immunoreactive neurons and their staining intensity were similar in the samples collected during the light and dark phase of the daily cycle. We did not record any differences in the pattern of immunostaining between the sexes.

\section{DISCUSSION}

Two antibodies directed against different parts of the CCAP pre-propeptide were used to determine the distribution of CCAP-like immunoreactivity in the cephalic ganglia of cockroaches. While the first antibody only detected the CCAP pre-propeptide the second detected both the prepropeptide and active peptide. Surprisingly, in the brain of $P$. americana, the antibody directed against the prepropeptide labelled only a small subset of immunoreactive neurons that were detected by the antibody directed against active CCAP. Neurons in ventrolateral protocerebrum and the dorsal median deutocerebrum detected by both antibodies seem to be identical. Also in G. portentosa the CCAP pre-propeptide was detected only in a few neurons at similar locations as those in $P$. americana. The low numbers of CCAP pre-propeptide immunoreactive neurons might be due to the short life of the pre-propeptide. The volume of pre-propeptide in particular cells could be undetectable using immunohistochemistry but sufficient for detection in the protein extract used in the Western blots. In addition, the antibody directed against the active peptide might have a higher affinity to the antigen. It is very unlikely that the active peptide is transported from a few neurons to many cells within the whole cephalic ganglia.

Fig. 5 (opposite page). CCAP-like immunoreactivity in the optic lobe, proto- and deutocerebrum of adult P. americana. A - a schematic diagram illustrating the topography of CCAP-producing cells in the adult brain (red a-s positions of the respective micrographs in this figure); B - two of about 5 small CCAP-immunoreactive cells located frontoventrally between the lobula and medulla in the optic lobe and the extensive arborization at the edges of the lateral lobula (arrowhead); $\mathrm{C}$ - microphotographs of three of about 5 of the large CCAP-positive cells in this region; D - the distribution of immunoreactive fibres in the optic lobe. There is a fine fibrous arborization in the median part of the medulla and on the inner lamina surface (black arrowheads). A single CCAP positive cell located in the proximal frontodorsal region of the optic lobe (black arrow). The cluster of CCAP positive neurons located at the base of the optic tract (white arrowhead). One of the CCAP-immunoreactive groups of cells in the posterior lateral protocerebrum (white arrow). E - two clusters of about 10 neurons in the posterior lateral protocerebrum with the somata lateral to the calyx of the mushroom body; $\mathrm{F}-\mathrm{The}$ nerve processes arising from CCAP-positive cells located in the lateral protocerebral cortex form a strong nerve bundle innervating the lateral region of the brain (arrowhead); $\mathrm{G}$ - CCAP-immunoreactive cells in the anterior dorsolateral protocerebrum; $\mathrm{H}$ - three of five strongly stained bilateral symmetrical neurons in the posterior pars intercerebralis; I - the representatives of about 45 CCAP-positive cells in the posterior pars intercerebralis. Arrowhead identifies another of the five bilateral symmetrical cells located in this area. J-CCAP-immunoreactive neurons in the anterior cortex of the midbrain; K - CCAP immunoreactivity in the pars intercerebralis and central body; L - one of the large (arrow) and one of the small cells (black arrowhead) located in the dorsolateral deutocerebrum. White arrowhead indicates the stained cells in the lateral protocerebral cortex. $\mathrm{M}$ - dorsolateral deutocerebrum has two large perikarya; N - CCAP-positive neurons in the dorsal median deutocerebrum. Scale bar (bottom right) $100 \mu \mathrm{m}$ (applies to all microphotographs without an internal bar). Abbreviations used in the schematic diagram and photographs: $\mathrm{AL}$ - antennal lobe; $\mathrm{CA}$ - corpora allata; $\mathrm{Ca}-$ calyx of the mushroom body; CB - central body; CC - corpora cardiaca; De - deutocerebrum; FG - frontal ganglion; La - lamina; Lo - lobula; Me - medulla; Oc - ocellus; OL - optic lobe; PI - pars intercerebralis; $\mathrm{Pr}$ - protocerebrum; SOG - suboesophageal ganglion; $\mathrm{Tr}$ - tritocerebrum. 






Fig. 6. CCAP-like immunoreactivity in the tritocerebrum, frontal and suboesophageal ganglion, and in the neurohemal organs of adult $P$. americana. A - two of about 15 CCAP-positive cells in the tritocerebrum with neuronal projections that extend into the ventral tritocerebrum (arrows); B - ramification of fibres in the frontal ganglion (FG) and in the frontal connective (FC) and recurrent nerve $(\mathrm{RN}) ; \mathrm{C}$ - extensive fibrous network and immunoreactive neurons in the frontal ganglion. Four to five of them are intensely stained (arrows). D - one of two large CCAP-positive cells located in the anterior part of the SOG; E - cells located in the posterior region of the SOG; F and G - CCAP-immunoreactive neurons on the ventral posterior surface of the SOG; H - dorsolateral parts of the SOG with two types of CCAP-immunoreacitve neurons: small (arrowheads) and large (arrows); I - small dorsolateral neuron with an axonal projection that extends to the median part of the SOG (arrow); J - high resolution microphotograph showing one of the large dorsolateral neurons; $\mathrm{K}$ - extensive fibrous arborization in the corpora cardiaca; $\mathrm{L}$ - fine varicose fibres in the corpora allata; $\mathrm{M}$ - immunoreactive fibres with varicosities in the nervus corpori cardiaci I (NCCI). Scale bar (bottom right) $100 \mu \mathrm{m}$ (applies to all microphotographs without an internal bar). 
The antibody directed against active CCAP detected CCAP-immunoreactive neurons of various sizes and staining intensities in the optic lobe, ventral and dorsal lateral protocerebrum, pars intercerebralis, deutocerebrum, lateral tritocerebrum, suboesophageal ganglion and frontal ganglion of $P$. americana. Their neuronal processes and fibres innervate almost all major areas in the cephalic ganglion, including the frontal ganglion and both neurohemal release organs. This widespread distribution of antigen closely resembles the CCAP immunoreactivity recorded in the locust, Locusta migratoria (Dircksen \& Homberg, 1995), stick insect, Baculum extradentatum (Lange \& Patel, 2005), crickets Dianemobius nigrofasciatus and Allonemobius allardi (Sehadova et al., 2007), but not the mealworm beetle, Tenebrio molitor and hawkmoth, Manduca sexta, in which only five or two pairs of CCAP-positive neurons, respectively, occur in the posterior midbrain of adults, and six pairs or one pair of neurons, respectively, exhibit CCAP immunoreactivity in the adult SOG (Breidbach \& Dircksen, 1991; Davis et al., 1993; Loi et al., 2001). In addition, in the mosquito, Anopheles gambiae there is only a restricted number of CCAP-positive neurons in the anterio-lateral and posterior protocerebrum, in the base of the optic lobe, the distal part of the medulla and SOG (Estévez-Lao et al., 2013). Similarly located CCAP- expressing cells, detected using in situ hybridization, occur in the protocerebrum of fifth instar nymphs of the blood sucking bug, Rhodnius prolixus (Lee et al., 2011).

In the locust and stick insect, the majority of the CCAPpositive neurons occur in the optic lobe. In P. americana, the optic lobe contains one CCAP-positive neuron in the proximal frontal dorsal region and a group of about 5 large and 5 small weakly staining neurons in the proximal frontal ventral region. This group resembles the cam-cells that occur in the optic lobe of locusts, stick insects and crickets, but the number of immunoreactive cells varies among species (Dircksen \& Homberg, 1995; Lange \& Patel, 2005; Sehadova et al., 2007). The cm-neurons that are very abundant in the optic lobes of locusts and stick insects did not occur in $P$. americana. In a few preparations we noticed that a considerable number of small cells located in this area were very weakly stained.

In the central brain of $P$. americana there are clusters of CCAP-positive neurons comparable to almost all the groups of CCAP-immunoreative cells in locusts, except groups cp4, cp5 and cp10, which occur in the locust protocerebrum. The neurons were in similar positions but the number of immunoreactive cells in some groups, especially in the deuto- and tritocerubrum, varied. In addition, there are CCAP-positive neurons in the anterior pars intererebralis and anterior cell cortex of the protocerebrum in $P$. americana, which also occur irregularly in locusts, which contrasts with cockroach where they were recorded in all preparations. The group of 5 intensely stained cells in the posterior pars intercerebralis in each brain hemisphere of $P$. americana are in similar positions and the intensity of labelling of the CCAP-positive neurons in this region is similar to that recorded for all other species of insects so far analyzed (Breidbach \& Dircksen, 1991; Davis et al., 1993; Dircksen \& Homberg, 1995; Loi et al., 2001; Lange \& Patel, 2005; Sehadova et al., 2007). Dircksen \& Homberg (1995) called these cells interspecies homologs.

The CCAP-immunoreactive neurons in the tritocerebrum of $P$. americana project well into the frontal ganglion, where there are a lot of CCAP-positive cells. In addition, in the stick insect the frontal ganglion contains 22 large CCAP-positive cells (Lange \& Patel, 2005). Unlike in the cockroach and stick insect, in a few preparations there is a single CCAP-immunoreactive neuron in the frontal ganglion of locusts (Dircksen \& Homberg, 1995). In crickets, there is one CCAP-positive cell in the tritocerebrum and 3-4 in the frontal ganglion (Sehadova et al., 2007).

The occurrence of CCAP-immunoreactive cells in the dorsal lateral regions of the SOG of cockroaches is partially in accordance with the distribution of CCAP-positive neurons in the SOGs of locusts and stick insects (Dircksen et al., 1991; Lange \& Patel, 2005) and the arrangement of CCAP-positive neurons in the middle area of the SOG partially resembles that recorded in crickets (Sehadova et al., 2007).

The presence of CCAP-like antigen in both neurohemal organs confirmed the neurohumoral function of CCAP in controlling moulting and eclosion. In this respect the expectation is that the expression of the CCAP gene is under the control of circadian and/or a photoperiodic clock, but our investigation did not reveal any significant daily changes in the abundance of CCAP-like antigen.

Studies of the gene encoding CCAP pre-propeptide indicate it is differently organized in different insects (Loi et al., 2001; Lee et al., 2011). This gene contains from two to four introns. In D. melanogaster, M. sexta and R. prolixus, one of the introns divides the short functional peptide coding sequence. The position of this intron is not universal. In Anopheles gambiae, the nucleotide sequence that encodes the active CCAP is not divided by an intron, although the pre-propeptide coding sequence contains a short intron (Estévez-Lao et al., 2013). The expected size of the CCAP pre-propeptide varies from 14 to more than $19 \mathrm{kDa}$ (Table 1). The size of the CCAP precursor in G. portentosa is about $15 \mathrm{kDa}$ (Fig. 4). This is similar to the results obtained by the in silico analysis of other species, but slightly different from the expected size of the CCAP precursor in $P$. americana. In a previous study on the cricket, D. $n i$ grofasciatus (Sehadova et al., 2007) the molecular weight of CCAP precursor determined by immunoblotting was 17 $\mathrm{kDa}$.

ACKNOWLEDGEMENTS. This study was supported by a Faculty of Biology and Environmental Protection internal grant for young scientists. HS acknowledges the use of research infrastructure that was funded by the European Union Seventh Framework Programme (FP7/2007-2013) under grant agreement $n^{\circ} 316304$.

\section{REFERENCES}

Arakane Y., Li B., Muthukrishnan S., Beeman R.W., Kramer K.J. \& PARK Y. 2008: Functional analysis of four neuropeptides, EH, ETH, CCAP and bursicon, and their receptors in 
adult ecdysis behavior of the red flour beetle, Tribolium castaneum. - Mech. Dev. 125: 984-995.

BRADFORD M.M. 1976: A rapid and sensitive method for the quantitation of microgram quantities of protein utilizing the principle of protein-dye binding. - Anal. Biochem. 72: 248-254.

BreidBach O. \& DirCKsen H. 1991: Crustacean cardioactive peptide-immunoreactive neurons in the ventral nerve cord and the brain of the meal beetle Tenebrio molitor during postembryonic development. - Cell Tissue Res. 265: 129-144.

Cazzamali G., Hauser F., Kobberup S., Williamson M. \& GrimMELIKHUIJZEN C.J. 2003: Molecular identification of a Drosophila $\mathrm{G}$ protein-coupled receptor specific for crustacean cardioactive peptide. - Biochem. Biophys. Res. Commun. 303: $146-152$

Da Silva S.R., Da Silva R. \& Lange A.B. 2011: Effects of crustacean cardioactive peptide on the hearts of two Orthopteran insects, and the demonstration of a Frank-Starling-like effect. - Gen. Comp. Endocrinol. 171: 218-224.

Davis N.T., Homberg U., Dircksen H., Levine R.B. \& HildeBRAND J.G. 1993: Crustacean cardioactive peptide-immunoreactive neurons in the hawkmoth Manduca sexta and changes in their immunoreactivity during postembryonic development. - J. Comp. Neurol. 338: 612-627.

Dircksen H. \& Homberg U. 1995: Crustacean cardioactive peptide-immunoreactive neurons innervating brain neuropils, retrocerebral complex and stomatogastric nervous system of the locust, Locusta migratoria. - Cell Tissue Res. 279: 495-515.

Dircksen H., Müller A. \& Keller R. 1991: Crustacean cardioactive peptide in the nervous system of the locust, Locusta migratoria: an immunocytochemical study on the ventral nerve cord and peripheral innervation. - Cell Tissue Res. 263: 439-457.

Donini A., Agricola H.J. \& Lange A.B. 2001: Crustacean cardioactive peptide is a modulator of oviduct contractions in Locusta migratoria. - J. Insect Physiol. 47: 277-285.

Donini A., NGo C. \& Lange A.B. 2002: Evidence for crustacean cardioactive peptide-like innervation of the gut in Locusta migratoria. - Peptides 23: 1915-1923.

Dulcis D., Levine R.B. \& Ewer J. 2005: Role of the neuropeptide CCAP in Drosophila cardiac function. - J. Neurobiol. 64: 259-274.

Estévez-Lao T.Y., Boyce D.S., Honegger H.W. \& Hillyer J.F. 2013: Cardioacceleratory function of the neurohormone CCAP in the mosquito Anopheles gambiae. — J. Exp. Biol. 216: 601613.

Furuya K., Liao S., Reynolds S.E., Ota R.B., Hackett M. \& SCHOOLEY D.A. 1993: Isolation and identification of a cardioactive peptide from Tenebrio molitor and Spodoptera eridania. - Biol. Chem. Hoppe-Seyler 374: 1065-1074.

Gammie S.C. \& TRuman J.W. 1997: Neuropeptide hierarchies and the activation of sequential motor behaviors in the hawkmoth, Manduca sexta. - J. Neurosci. 17: 4389-4397.

Jackson G.E., Mabula A.N., Stone S.R., Gäde G., Kövér K.E., SZILÁgYI L. \& VAN der Spoel D. 2009: Solution conformations of an insect neuropeptide: Crustacean cardioactive peptide (CCAP). - Peptides 30: 557-564.

LANGE A.B. \& PATEL K. 2005: The presence and distribution of crustacean cardioactive peptide in the central and peripheral nervous system of the stick insect, Baculum extradentatum. Regul. Pept. 129: 191-201.

Lee D.H., Paluzzi J.P., Orchard I. \& Lange A.B. 2011: Isolation, cloning and expression of the crustacean cardioactive peptide gene in the Chagas' disease vector, Rhodnius prolixus. - Peptides 32: 475-482.
Lehman H.K., Murgiuc C.M., Miller T.A., Lee T.D. \& HildeBRAND J.G. 1993: Crustacean cardioactive peptide in the sphinx moth, Manduca sexta. - Peptides 14: 735-741.

Lor P.K., Emmal S.A., Park Y. \& Tublitz N.J. 2001: Identification, sequence and expression of a crustacean cardioactive peptide (CCAP) gene in the moth Manduca sexta. - J. Exp. Biol. 204: 2803-2816.

Matsui T., Sakai T., Satake H. \& Takeda M. 2013: The pars intercerebralis affects digestive activities of the American cockroach, Periplaneta americana, via crustacean cardioactive peptide and allatostatin-A. - J. Insect Physiol. 59: 33-37.

PARK Y., KIM Y.J. \& ADAMS M.E. 2002: Identification of G proteincoupled receptors for Drosophila PRXamide peptides, CCAP, corazonin, and AKH supports a theory of ligand-receptor coevolution. - Proc. Natl. Acad. Sci. U.S.A. 99: 11423-11428.

Phlippen M.K., Webster S.G., Chung J.S. \& Dircksen H. 2000: Ecdysis of decapod crustaceans is associated with a dramatic release of crustacean cardioactive peptide into the haemolymph. - J. Exp. Biol. 203: 521-536.

Sakai T., Satake H., Minakata H. \& Takeda M. 2004: Characterization of crustacean cardioactive peptide as a novel insect midgut factor: isolation, localization, and stimulation of $\alpha$-amylase activity and gut contraction. - Endocrinology $\mathbf{1 4 5}$ : 5671-5678.

Sakai T., Satake H. \& Takeda M. 2006: Nutrient-induced alphaamylase and protease activity is regulated by crustacean cardioactive peptide (CCAP) in the cockroach midgut. - Peptides 27: $2157-2164$.

Sehadová H., Shao Q.M., Sehnal F. \& Takeda M. 2007: Neurohormones as putative circadian clock output signals in the central nervous system of two cricket species - Cell Tissue Res. 328: 239-255.

SlÁma K. \& RosińsKi G. 2005: Delayed pharmacological effects of proctolin and CCAP on heartbeat in pupae of the tobacco hornworm, Manduca sexta. - Physiol. Entomol. 30: 14-28.

Sláma K., SAKai T. \& TaKeda M. 2006: Effect of corazonin and crustacean cardioactive peptide on heartbeat in the adult American cockroach (Periplaneta americana). - Arch. Insect Biochem. Physiol. 62: 91-103.

Stangier J., Hilbich C., Beyreuther K. \& Keller R. 1987: Unusual cardioactive peptide (CCAP) from pericardial organs of the shore crab Carcinus maenas. - Proc. Natl. Acad. Sci. U.S.A. 84: 575-579.

Stangier J., Hilbich C., Dircksen H. \& Keller R. 1988: Distribution of a novel cardioactive neuropeptide (CCAP) in the nervous system of the shore crab Carcinus maenas. - Peptides 9: 795-800.

Stangier J., Hilbich C. \& Keller R. 1989: Occurrence of crustacean cardioactive peptide (CCAP) in the nervous system of an insect, Locusta migratoria. - J. Comp. Physiol. (B) 159: 5-11.

Veelaert D., Passier P., Devreese B., Vanden Broeck J., Van Beeumen J., Vullings H.G.B., Diederen J.H.B., Schoofs L. \& DE Loof A. 1997: Isolation and characterization of an adipokinetic hormone release-inducing factor in locusts: the crustacean cardioactive peptide. - Endocrinology 138: 138-142.

Vehovgzky A., Agricola H.J., Elliott C.J., Ohtani M., KárPÁti L. \& HERnÁdi L. 2005: Crustacean cardioactive peptide (CCAP)-related molluscan peptide (M-CCAPs) are potential extrinsic modulators of the buccal feeding network in the pond snail Lymnaea stagnalis. — Neurosci. Lett. 373: 200-205.

Received May 12, 2014; revised and accepted December 12, 2014 Prepublished online February 3, 2015 